\title{
Po-Shen Loh Makes Good
}

\section{Sophia D. Merow}

The Hertz Foundation has never defined national emergency for Po-Shen Loh. Nor can the nonprofit that funded the Carnegie Mellon mathematician's doctoral study compel him to take action in the event of war or natural disaster. But when Loh accepted the prestigious Hertz Fellowship in 2004, he signed a "nonbinding moral commitment" to make his skills available to the United States "in times of national emergency." And he has not forgotten.

Which is not to say that Loh has always had a clear vision of how he might pitch in during a crisis. Far from it.

To land the Hertz Fellowship, Loh underwent a rigorous application and interview process that involved convincing astrophysicist and prolific inventor Lowell Wood of the real-world usefulness of his prospective research. (Hertz Fellows are PhD students in the applied physical, biological, and engineering sciences; of the more than 1200 fellows named since 1963, fewer than 100 studied mathematics.) More than 15 years later, Loh still remembers the case he made to Lowell when pressed about the potential applicability of his work. He spoke about error-correcting codes-how they enable reliable delivery of digital data over unreliable communication channels-and expected his interviewer to nod approvingly and move on to the next question. No such luck.

Wood rattled off a list of requirements and asked Loh to produce a code that satisfied them. Fazed at first, and less conversant in error-correcting codes than his glib reference to them implied, Loh was nonetheless able, over the next five or ten minutes, to construct a suitable code.

Loh had honed this ability to think on his feet over years of involvement in competition math. As a middle school student, he twice represented Wisconsin in the

Sophia D. Merow is a freelance writer and editor. Her email address is sdmerow@gmai 1. com. This piece is based primarily on interviews conducted with Loh in October 2020.

For permission to reprint this article, please contact: reprint-permission aams.org.

DOI: https://dx.doi.org/10.1090/noti2342
MATHCOUNTS national championships; ${ }^{1}$ in high school he earned a silver medal as part of the US contingent at the 1999 International Mathematical Olympiad (IMO).

Loh credits these competitions with exposing him to math categorically different from the rote procedures typically taught in school. "If I looked at a question," Loh says of his youthful experience of mathematics, "I would actually have the expectation not to immediately know how to do it." He sat for each contest prepared to muster his conceptual resources and, through clever combination of these, reason his way to solutions.

Besides sharpening his problem-solving skills, math contests afforded Loh an early-if modest-opportunity to act upon his inborn impulse to help. As a high school student, he helped coach a middle school math team; while an undergrad at Caltech, he helped train the USA IMO team as a student assistant. Loh relished the challenge of explaining concepts to the next generation of mathletes and saw coaching as a way to give back to a system from which he had benefitted. He recognized in the up-and-comers the same motivation and mathematical curiosity that drove him.

Then, in 2013, the Mathematical Association of America named Loh (who had served as Deputy Team Leader for three years) National Coach of the USA IMO team, ${ }^{2}$ and he began to dream bigger. With the new title, Loh reckoned, came if not power exactly, at least influence, and with that, responsibility. He could, as National Coach, focus on helping the top math students in the country do as well as possible on the annual international contests, ${ }^{3}$ but Loh interpreted his charge more broadly. He decided to mount a year-round effort to turn more people on to mathematics.

\footnotetext{
${ }^{1}$ In 2019, Loh's daughter Vivian, the first girl ever to win the Pennsylvania MATHCOUNTS competition, represented that state in the national championships.

${ }^{2}$ The MAA selects the students and coaches who participate in the IMO, registers with the IMO organization, and financially supports Team USA's travel.

${ }^{3}$ The country's top math students have in fact done remarkably well during Loh's tenure as National Coach. Team USA took back-to-back IMO victories in 2015 and 2016 (having not won since 1994), again beat out the competition in 2018, and in 2019 tied with China for top honors.
} 


\section{COMMUNICATION}

One inspiration to Loh as he zeroed in on his mission to bring math to the masses was John Mackey, his colleague in the Carnegie Mellon math department. Loh remembers being struck by Mackey's stated aim in teaching a calculus course for non-majors. "He said his goal was to convert as many of them to math majors as possible by the end of the semester," Loh recalls. "He was going to evangelize." Talking to Mackey-and watching Mackey perform ("watching him teach was like watching him perform," Loh clarifies) prompted Loh to not only ponder the value of inviting the uninitiated into mathematics but also start devising strategies for doing so.

Loh has split the problem of getting more people engaged in mathematics into two. People must be motivated to learn mathematics-that's one. And then there must be effective and accessible ways for them to learn it once they want to. Loh's solution-in-progress for the second subproblem is the free individualized learning website Expii.

When Loh and a handful of Carnegie Mellon students began developing Expii in 2013, they envisioned a website populated by crowdsourced math and science lessons valuated by users' up- and down-votes and catering to a diversity of learning styles. (A "written word person" with an affinity for diagrams, Loh recognizes that others might gravitate more toward, say, video explanations.) Although Loh imagined it would be easy to build an online resource as popular as Wikipedia- "We'll be done in like a month," he remembers thinking - the project did not take off overnight. Crowdsourcing produced material at a slower pace than expected, for one thing, and a mismatch emerged between the interests of those contributing to the site and the needs of the average seeker of online STEM support.

And even when the Expii team brought the creation of lessons in-house, they didn't get it right right away. They reconceived high school algebra to incorporate theoretical ideas typically not encountered until a college introduction to modern algebra, only to discover that, as Loh puts it, "not everyone cares about that." So the team regrouped, polled some high schoolers, and tailored Expii's offerings to what students actually want: digestible multimedia presentations of content covered in school. Taking development cues from the web's most searched math and science questions (and sticking with the original plan to provide multiple explanations of any one concept), Expii found its audience-those struggling with pre-algebra and Algebra I-at last.

"I guess the attitude that we've taken with this is if it doesn't work, make it work, somehow," says Loh. "And work might mean change the idea. Maybe someday we'll teach everyone abstract algebra, but not now."

Proceeding in parallel to Expii's evolution and expansion, Loh's effort to address the other subproblem he had identified-that of motivation to learn-is what he calls a "PR campaign for math." Write a mathematician into a sitcom or a blockbuster film, and he or she will necessarily have flaws, Loh realized, because conflict fuels storylines. Watch a commercial, in contrast, and it's all strengths. For math to be as fetching as Coca-Cola or basketball, Loh concluded, it needs advertising.

"And that's when I really started trying to hit the mainstream," he says.

In light of insights provided by a public relations firm the Overdeck Family Foundation engaged on his behalf, Loh revised his understanding of what constitutes math outreach. He took improvisational comedy classes for a year to prepare for co-appearances with social media influencers. Search his name on YouTube and, in addition to the anticipated lecture footage, there's video of Loh airborne in a cheer squad's basket toss, of him talking chords with an America's Got Talent alum. To reach people, Loh has learned, it helps to meet them where they are, to start the conversation by finding the mathematical, the analytical, the thinking in whatever it is that already interests them.

Driving all of Loh's educational initiatives-Expii and the video collabs, the public lectures he gives around the world, and Daily Challenge, the paid series of online middle school math courses the proceeds of which fund his other projects-is his conviction that mathematics is "a sandbox for logic," an ideal context in which to develop more broadly applicable ingenuity.

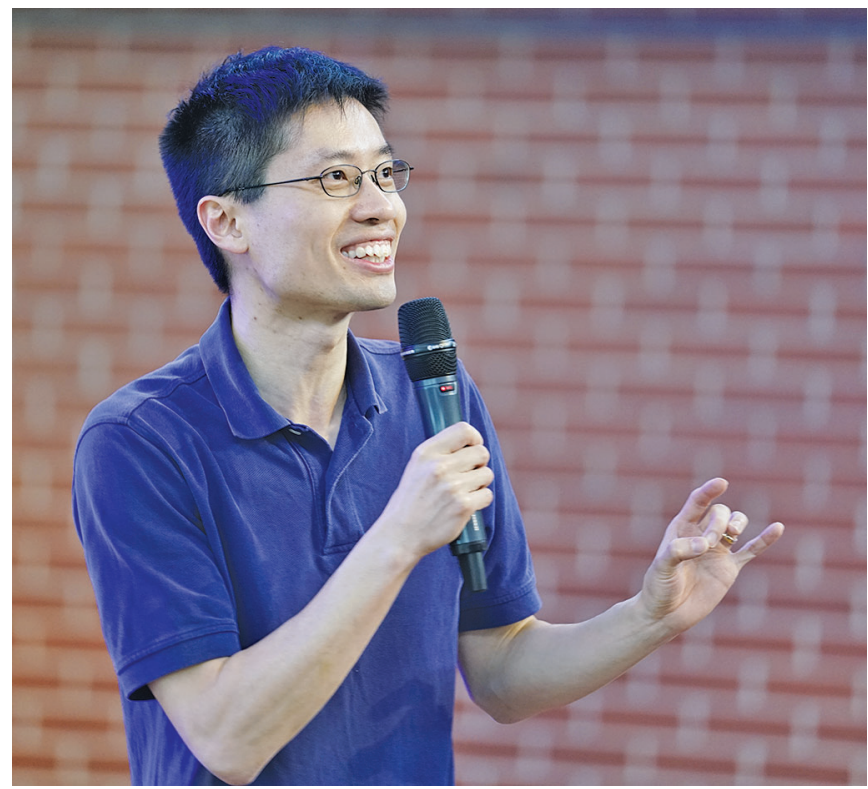

Figure 1. In public math talks, Loh aims to entertain as well as educate.

"If people learn how to approach any task by thinking and using intellectual creativity to come up with approaches, then they are able to solve a lot of different kinds of questions," he says.

And Loh can, if pressed, articulate a very specific - and lofty—goal for global mathematical attainment. It involves 
the American Invitational Mathematics Examination (AIME)-the three-hour, 15-question exam given to high schoolers who excel in the first round of the Mathematical Association of America's American Mathematics Competitions-and Problem 1 thereon. $^{4}$

"If at least half of all people could do that first question in 24 hours, I would consider that to be a great outcome," Loh says. You needn't know calculus to solve Problem 1, he explains, but you must deeply understand concepts, leverage connections between them, conduct a systematic inquiry. "So that's actually what I care about when I say I want people to learn math."

Much as educators and op-ed authors bemoan innumeracy and the dearth of critical thinking skills in the public at large, these deficits have not achieved the undisputed emergency status of the pandemic that swept the globe in the early weeks and months of 2020.

On March 14-he remembers the date, because, $\mathrm{Pi}$ Day-Loh and a number of other Hertz Fellows received an email from a senior member of the community. The message emphasized the gravity of the COVID-19 threat and reminded recipients of their moral commitment. "Now is as appropriate a time as ever to engage in this because it's not only a national emergency, it's an international emergency," Loh paraphrased when we spoke in October. "So if you have anything that you can do to help, jump in."

Loh wasn't sure at first how he could help. Online education was one possibility, given his Expii and Daily Challenge work and the increased need for remote learning resources as schools shuttered. Every weekday from March 16 through July 3, he held hour-plus "Ask Math Anything" live streams during which he improvised (remember those improv classes?) mini-lessons around questions posed by participants in the YouTube Live interactive chat. He addressed such queries as "How do you generate true randomness?" and "What is the most famous triangle you know?"

Loh found his real COVID calling, however, while reading the draft thesis of his PhD student, Debsoumya Chakraborti, on March 15. As he parsed the first sentence of the introduction-"In extremal graph theory, there are many recent works in the literature involving maximizing the number of complete subgraphs under certain natural conditions..." - it hit him like a flash: COVID-19 and graph theory are deeply related. If you could anonymously collect information about who spends time with whom and which people have tested positive for the novel coronavirus, Loh reasoned, you could use that network to provide yet

${ }^{4}$ Problem 1 on 2020 AIME I: In $\triangle A B C$ with $A B=A C$, point $D$ lies strictly between $A$ and $C$ on side $\overline{A C}$, and point $E$ lies strictly between $A$ and $B$ on side $\overline{A B}$ such that $A E=E D=D B=B C$. The degree measure of $\angle A B C$ is $\frac{m}{n}$, where $m$ and $n$ are relatively prime positive integers. Find $m+n$.

Problem 1 on 2020 AIME II: Find the number of ordered pairs of positive integers $(m, n)$ such that $m^{2} n=20^{20}$. uninfected people with advance alerts of approaching threat. His mind was racing.

An hour later, having researched the capabilities of current smartphones, Loh emerged from his home office for an additional reality check. "If somebody made an app that let you see if COVID was coming," he asked his wife, Debbie Lee, "would you actually download an app like this?"

A spousal affirmative in hand-and buoyed by confidence born of six years working with user experience designers and software engineers to build Expii-Loh resolved to make the app a reality.

"We'll be done in a week," he told his team.

"Now a week later we weren't done," Loh admits. "But my personality is, once I decide to do something, I like to solve the problem."

Loh has a researcher's disinterest in retracing paths already trodden, so he forged ahead on the nascent NOVID (an elision of no and COVID) project only because he didn't see anyone else implementing anything like what he had in mind. Standard contact tracing relies on our willingness to make personal sacrifice for the public good: an individual is notified only after interaction with an infected person and is at that point requested to quarantine- to protect others. The network-enabled app Loh envisioned would "flip the incentive structure." Allow users to monitor infection rates among contacts of contacts of contacts, and you enable them to gauge their risk of infection and take precautions to mitigate it. Loh hypothesized that by facilitating strategic, self-interested behavior modification-more scrupulous masking, perhaps, or fewer trips to the grocery store-a system like NOVID could dampen the spread of the virus without the collateral damage associated with more drastic measures such as lockdowns.

Loh and a crack team of engineers, designers, and algorithmists had a beta version of NOVID up and running in April 2020, and they've been fine-tuning it ever since. Using a combination of ultrasound, Bluetooth, and Wi-Fi technologies, the app builds an anonymous network of users based

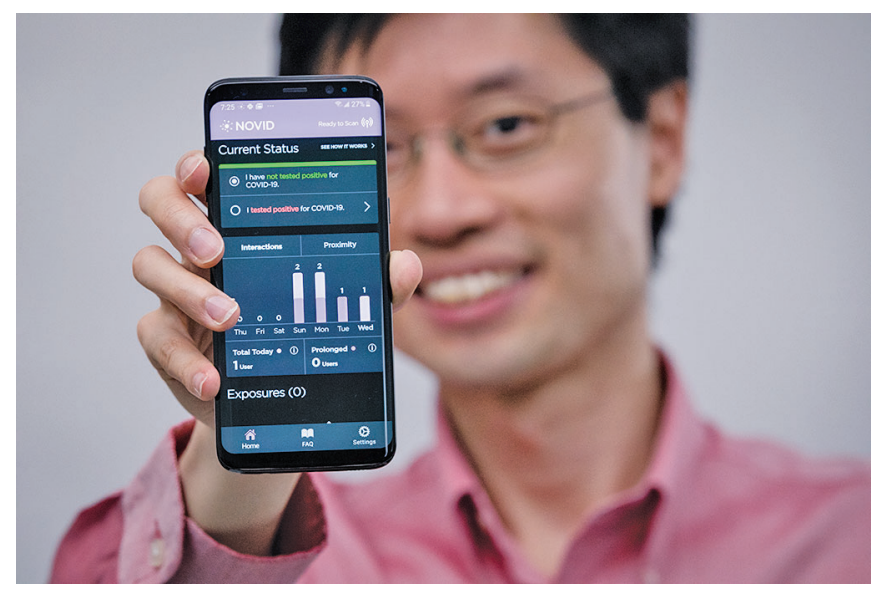

Figure 2. NOVID bills itself as "your personal COVID-19 radar." 
on interactions between devices and provides "pre-exposure awareness" via a bar-graph display of COVID positives up to twelve degrees of separation away.

For all its uniqueness and promise, NOVID did not catch on immediately upon release. Many assumed it was like every other contact-tracing app, a privacy-imperiling dispenser of stay-at-home directives. In articulating NOVID's in fact paradigm-shifting approach, Loh leans on the language of flipping, inversion, commutativity. "If I can reverse the order of two words in a fundamental way," he says, "then we've contributed something." NOVID doesn't track you, it helps you track COVID. "Once people understand this then suddenly it's easy to get adoption."

Loh is concerned less with adoption of NOVID specifically than with the widespread deployment of systems like it. To speed global uptake of NOVID-style pre-exposure notification, Loh exploits networks of the social variety, seeking out receptive audiences incrementally closer to decision makers in city, state, and national governments. "Right now the aspiration is to try to help give all of humanity a different type of tool to fight all pandemics forever," he told me in October. "Let all of humanity make their own version of this different approach."

Even as he works to equip the world to better respond to pandemics present and future-while not dropping the ball on his math education efforts-Loh contests any suggestion that he does "so much." "Everyone is doing a lot," he says, proposing that the projects he has undertaken are simply more visible.

Nor does Loh attribute his successes to superior intellect or his unflappably upbeat demeanor to some mindfulness practice or exercise regimen. He is not better at math, he stresses, than the students he has coached to victory in the International Math Olympiad. His Expii and NOVID hires, mission-driven and ethically grounded, really know their stuff. Loh credits his PhD advisor, Benny Sudakov, with teaching him to speak more slowly and with more forethought, to build on past results rather than trying to reinvent the wheel over and over, to move beyond flawless completion of assignments-Loh graduated first in his class at Caltech, with a 4.3 GPA-and begin framing his own challenges. Working with Sudakov, Loh says, "taught me to figure out what to do."

And that buoyant disposition? Loh says he has his wife to thank for that. He and Lee met during freshman orientation at Caltech and married the day before their graduation. "She's been my partner through everything."

Loh expresses admiration for the breadth of his sometime interviewer Lowell Woods' knowledge and achievements, and for the audacity of Elon Musk and Bill Gates, such visionaries' willingness to go after stretch goals despite the very real risk of failure. He marvels too at how Terence Tao has systematically mastered and made significant contributions to one mathematical subfield after another.

"This shows that it's possible to keep picking up different things," Loh says, observing that, as his extracurricular activities have diversified, he has had to sequentially get up to speed in new disciplines. One can get a PhD in about five years, Loh muses. "Maybe that means it takes five years to become a pretty good expert in an area, and if you just do another five years and another five years and another five years you start picking up more and more and more areas. If I look at my life, basically every five years I'm picking up from some other domain."

To what domain will Loh apply himself next? What high-profile problem will he next help solve? Stay tuned.

\section{Yes, And}

Loh balks at advising fellow mathematicians to pursue any particular extracurricular endeavor-who is he to second-guess colleagues' allocation of scant time and energy?--but he does, under duress, humbly submit one recommendation: take improv classes. Internalizing improv's yes, and principle of interpersonal interaction, he says, has been "immensely useful." Show up, stipulates yes, and, and no matter what the other person says, find value in it, find some way to affirm it, and only then try to put your own spin on things. The yes, and habit makes for more effective math proselytizing, and there's a tangible benefit within academe as well: "After doing the improv comedy classes, my class prep time for teaching dropped like a stone," Loh reports. Improv taught him to ad-lib, to produce in a beat a suitable response to anything an undergrad might utter in, say, a first course in discrete math. And Loh no longer experiences any pre-presentation nerves, whether he's addressing a lecture hall of first-years or a head-of-state's right hand: "You just know if anything goes wrong you've gotten the experience of how to get back up and almost even make it look like it was intentional."

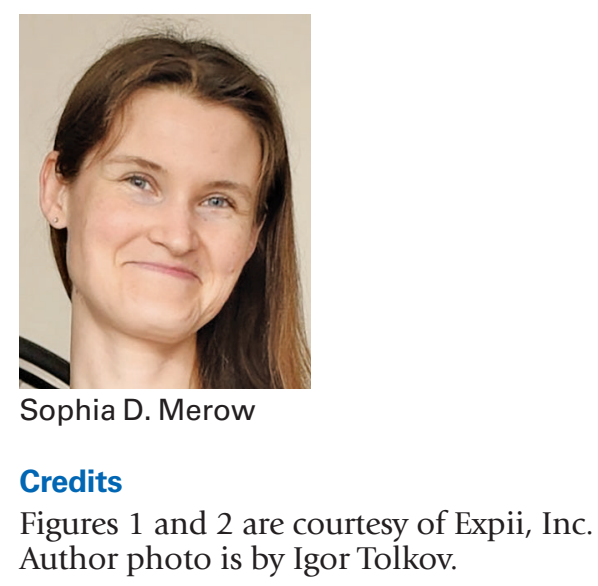

